\title{
Case of Insulinoma Misdiagnosed as a Psychiatric Condition for Five Months in Lattakia, Syria
}

\author{
Mansour $\mathbf{M}^{1 *}$, Salman $\mathbf{R}^{1}$, Ahmad $\mathrm{I}^{2}$ and Alloush \\ $\mathbf{A}^{3}$ \\ ${ }^{1}$ Department of Endocrinology, Faculty of Medicine, \\ Tishreen University, Syria \\ ${ }^{2}$ Department of Pathology, Faculty of Medicine, Tishreen \\ University, Syria \\ ${ }^{3}$ Department of Surgery, Faculty of Medicine, Tishreen \\ University, Syria \\ *Corresponding author: Mansour M, Endocrinology \\ Department, Tishreen University. Rabieh Square, \\ Building 2200, Tartous, Syria
}

Received: December 03, 2017; Accepted: J anuary 05, 2018; Published: J anuary 25, 2018

\begin{abstract}
Insulinomas are rare tumors of pancreas. These tumors produce insulin causing hypoglycemia which leads to severe asthenia, profuse diaphoresis and tremors. Occasionally they present with neurologic symptoms, therefore they are usually undiagnosed or misdiagnosed as behavior disturbances or psychiatric conditions. Many procedures can be used to localize the tumor and in most cases surgery is curative. Tumor enucleation is a procedure of choice, particularly in cases of small and isolated nodule that does not invade the pancreatic or bile ducts. Here we describe a case of a female patient with insulinoma presented with occasional loss of consciousness, depression, changes in personality and behavior for six months and barely responded to selective serotonin reuptake inhibitors. Once the diagnosis was made and the surgical therapy was carried out, our patient totally recovered and ended the psycho-drugs.
\end{abstract}

Keywords: Insulinoma; Psychiatric; Depression; Behavior; Personality changes

\section{Abbreviations}

SSRIs: Selective Serotonin Reuptake Inhibitors; ER: Emergency Room; BP: Blood Pressure; RR: Respiratory Rate; HR: Heart Rate; TSH: Thyroid Stimulating Hormone; CT: Computerized Axial Tomography; H\&E stain: Haematoxylin and Eosin stain

\section{Introduction}

Insulinomas are rare tumors of pancreas. They are benign in more than $90 \%$ of cases [1]. Delays in diagnosis of insulinoma are common because there may be a misattribution of the symptoms to psychiatric, cardiac, or neurological disorders. Duration of symptoms before diagnosis can reach 12-18 months on average. Our patient waited 5 months for the proper diagnosis and recovered totally after surgery [1,2].

\section{Case Presentation}

A 51-year-old Syrian female had a history of episodic and repetitive symptoms of profuse diaphoresis, tremors, palpitations, behavior and personality changes and occasional loss of consciousness for 6 months. Those symptoms occurred mainly at night and early morning, not related to meals but were relieved with oral carbohydrates intake. She had no medical history of endocrine disease. She was not a smoker and had no alcohol intake. She presented to the emergency department with symptoms of confusion, profuse diaphoresis, palpitation, fatigue. She appeared anxious. On examination her BP105/60 mmHg, HR100 per minute, RR18 per minute, and Spo2 was $99 \%$ with ambient air. The rest of her examination was unremarkable. Her random blood glucose showed a severe hypoglycemia $(42 \mathrm{mg}$ / dl). Blood samples were taken then she was treated with hypertonic glucose solution with an important resolution of symptoms. She was admitted to the endocrine department at Tishreen University hospital. On the ward, the Blood laboratory which were sampled
Table 1: Serum Glucose and hormone levels drawn in ER.

\begin{tabular}{|c|c|c|}
\hline & Serum level & Reference range \\
\hline Glucose & $42 \mathrm{mg} / \mathrm{dl}$ & $70-110 \mathrm{mg} / \mathrm{dl}$ \\
\hline Insulin & $9.8 \mu \mathrm{lU} / \mathrm{ml}$ & $2.6-24.9 \mu \mathrm{IU} / \mathrm{ml}$ \\
\hline Peptide-C & $1.2 \mathrm{ng} / \mathrm{ml}$ & $1.1-3.3 \mathrm{ng} / \mathrm{ml}$ \\
\hline Cortisol $(8 \mathrm{am})$ & $13.64 \mathrm{ug} / \mathrm{dl}$ & $6.4-21 \mathrm{ug} / \mathrm{dl}$ \\
\hline TSH & $1.93 \mu \mathrm{lU} / \mathrm{ml}$ & $0.5-6 \mu \mathrm{lU} / \mathrm{ml}$ \\
\hline
\end{tabular}

TSH: Thyroid Stimulating Hormone

Table 2: Blood laboratory results after supervised fasting evaluation.

\begin{tabular}{|c|c|c|}
\hline & Serum level & Reference range \\
\hline Glucose & $46 \mathrm{mg} / \mathrm{dl}$ & $70-110 \mathrm{mg} / \mathrm{dl}$ \\
\hline Insulin & $15.1 \mu \mathrm{lU} / \mathrm{ml}$ & $2.6-24.9 \mu \mathrm{lU} / \mathrm{ml}$ \\
\hline Peptide-C & $2.93 \mathrm{ng} / \mathrm{ml}$ & $1.1-3.3 \mathrm{ng} / \mathrm{ml}$ \\
\hline
\end{tabular}

in ER came and are shown in (Table 1). In the following morning a supervised fasting evaluation was performed and resulted in an episode of symptomatic hypoglycemia with hyperinsulinemia as shown in (Table 2). We decided to stop selective serotonin reuptake inhibitors (SSRIs). Urine for sulfonylurea screen was not preformed because it was not available in our institution, and the patient denied taking any medication. Abdominal echo revealed a kidney cyst measured 20 X 28 X $37 \mathrm{~mm}$. Other hormonal studies were normal. Upper and lower gastric endoscopy were normal. During admission, the patient was on multiple meals daily, and strict glucose observation. The episodes were relieved by oral carbohydrate intake. Abdominal CT demonstrated a hyper-vascular lesion involving tail of pancreas, measuring $22 \times 15 \mathrm{~mm}$, with enhancement during the arterial phases of contrast bolus (Figure 1). Tumor enucleation was performed, the material was fixed in formalin $10 \%$, then processed routinely using $\mathrm{H} \& \mathrm{E}$, and immunohistochemistry. Macroscopically 




Figure 1: Abdominal CT demonstrating a hyper-vascular lesion involving tail of pancreas, measuring $22 \times 15 \mathrm{~mm}$, with enhancement during the arterial phases of contrast bolus.

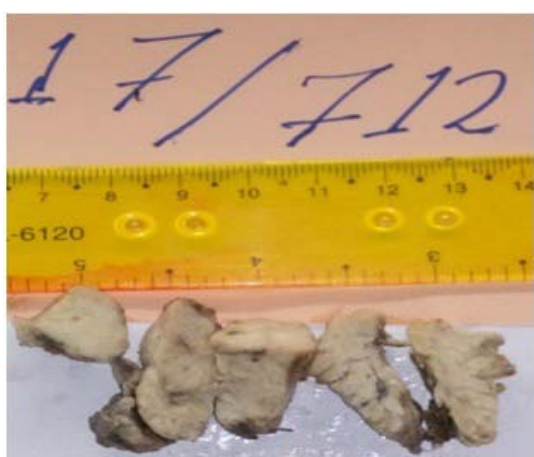

Figure 2: Macroscopically after fixation.

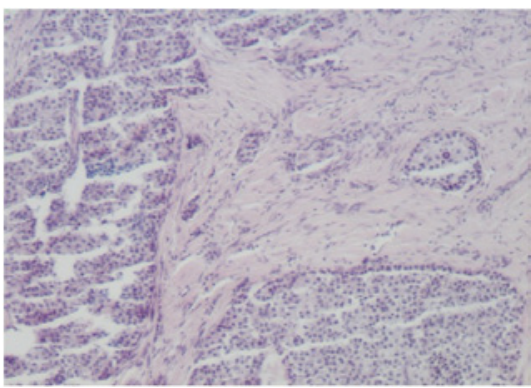

Figure 3: Invasive neoplastic components (X 10x10).

ill-demarcated mass, measuring $1.7 \mathrm{~cm}$, cut sections were white showing micro cysts (Figure 2 and 3), microscopic picture exhibits invasive small, relatively uniform cuboidal cells with centrally located nuclei, nuclear enlargement, solid sheets or nest with Rosette-like gland formation, cystic spaces, mitotic figures are 2 mitoses/10 HPF (Figure 4). Chromogranin A +++, Ki-67+ cells $<2 \%$ (Figure 5 and 6). Complementary staining for insulin was not performed because it is not available. Therefore, a well differentiated insulinoma of pancreas was identified. Regarding to functional status and biological behavior, diagnosis of pancreatic insulinoma was confirmed. After surgical treatment, the glucose level increased to the normal range immediately. The patient was discharged after 3 days with no hypoglycemic symptoms. The patient remains asymptomatic during the five-month follow-up.

\section{Discussion}

Insulinomas are rare tumors of the Langherhans islets. They are

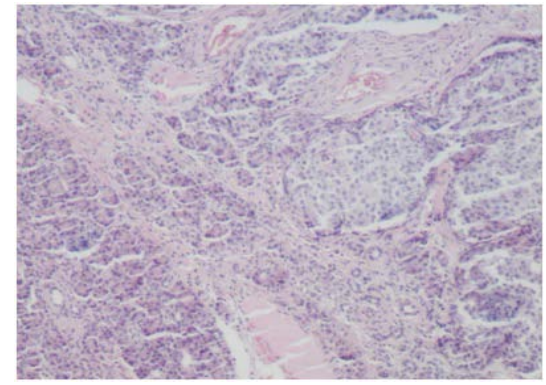

Figure 4: Invasive neoplastic components (X 10x10).



Figure 5: IHC insulinoma chromogranin a positive $\mathrm{X} 10 \times 10$.

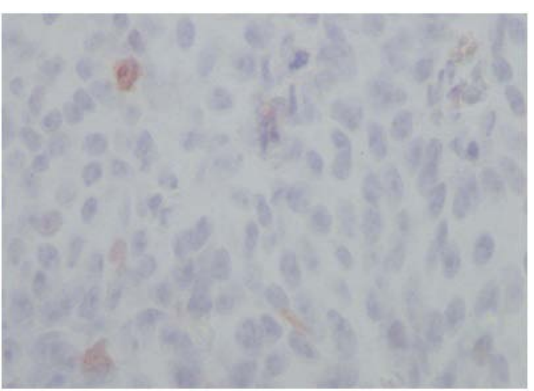

Figure 6: Ki-67+(X 10×40)

benign in most of cases, occurring in 1-4 per million of the population per year. Furthermore, these tumors rarely occur as part of Multiple Endocrine Neoplasia Syndrome type I (MEN I). Most patients are older than 50 [1].

Diaphoresis, tremors, and palpitations are common autonomic symptoms of insulinoma. On the other hand, neuroglycopenenic symptoms include confusion, behavior and personality changes, visual disturbances, seizures and coma [3]. Our patient suffered from confusion, depression, behavior and personality changes for almost 6 months before the diagnosis. She went to a hospital where she was told that here condition is psychic in origin due to the last terrorist attacks in her city. When she came to our hospital the lab blood tests showed a severe hypoglycemia. We administered IV hypertonic glucose solution with an important resolution of symptoms. These match the criteria of Whipple's triad, which are:

1. Hypoglycemia (plasma glucose $<50 \mathrm{mg} / \mathrm{dL}$ ).

2. Neuroglycopenic symptoms.

3. Prompt relief of symptoms following the administration of 
glucose [4]

It is known that plasma insulin concentration which is more than 3 micro U/mL (20.8 pmol/L) when the plasma glucose concentration is less than $55 \mathrm{mg} / \mathrm{dL}(3.0 \mathrm{mmol} / \mathrm{L})$ indicates an excess of insulin, we must consider reasons for hyperinsulinemia e.g. insulinoma, oral hypoglycemic agent [5].

Supervised fasting evaluation was performed and resulted in an episode of symptomatic hypoglycemia with hyperinsulinemia. Multiple endocrine neoplasias were excluded because other hormonal studies were normal and no other masses were revealed in CT scan.

Once a clinical and biochemical diagnosis was established, many imaging modalities were used to localize the tumor. The choice of procedure depends upon which tests are available and the local radiologic skills [6].

Nowadays, CT scan is accepted worldwide as the first-line investigation for the detection of insulinomas [7]. It is considered as a safe and simple procedure that detects the exact location of insulinoma, and gives us information about its relationship to vital structures, and the presence of metastases [8]. Our patient's CT scan demonstrated a hyper-vascular lesion involving tail of pancreas, with enhancement during the arterial phases of contrast bolus, without liver metastasis or intra-abdominal lymph nodes (Figure1).

After identification of insulinoma, surgery is indicated for all localized tumors. The choice of procedure is highly dependent on the features of the tumor mass, including its type, size, and localization. Various atypical resections, including enucleation, partial and middle pancreatectomy have the advantage of preserving the pancreatic parenchyma as much as possible, hence reducing the risk of late exocrine/endocrine function insufficiency [9]. Tumor enucleation was performed at Tishreen University Hospital.

Histologically, a well differentiated insulinoma of pancreas was identified (according to WHO committee for histological typing of endocrine tumors).
By presenting this case we would like to emphasize the importance of considering neuroglycopenia in all patients who present common problems such as spells, psychological complaints, altered memory or seizure disorders. Insulinoma could be cured with surgery, and early recognition may prevent serious adverse results including neurological damage.

\section{Acknowledgment}

The authors would like to thank Reem Mansour for reviewing the article.

\section{References}

1. Tarchouli M, Ali AA, Ratbi MB, Belhamidi MS, Essarghini M, Aboulfeth EIM, et al. Long-standing insulinoma: two case reports and review of the literature. Tarchouli et al. BMC Res Notes. 2015; 8: 444.

2. Kar P, Price P, Sawers S, Bhattacharya S, Reznek RH, Grossman AB Insulinomas may present with normoglycemia after prolonged fasting but glucose-stimulated hypoglycemia. J Clin Endocrinol Metab. 2006; 91: 47334736.

3. Suzuki K, Miyamoto M, Miyamoto T, Hirata K. Insulinoma with early-morning abnormal behavior. Intern Med. 2007; 46: 405-408.

4. Rostambeigi N, Thompson GB. What should be done in an operating room when an insulinoma cannot be found? Clin Endocrinol (Oxf). 2009; 70: 512515.

5. Fajans SS, Floyd JC Jr. Fasting hypoglycemia in adults. N Engl J Med. 1976; 294:766.

6. Tucker ON, Crotty PL, Conlon KC. The management of insulinoma. $\mathrm{Br} \mathrm{J}$ Surg. 2006; 93: 264-275.

7. Okabayashi T, Shima $Y$, Sumiyoshi T, Kozuki A, Ito S, Ogawa $Y$, et al. Diagnosis and management of Insulinoma. World J Gastroenterol. 2013; 19: 829-837.

8. McAuley G, Delaney H, Colville J, Lyburn I, Worsley D, Govender P, et al. Multimodality preoperative imaging of pancreatic insulinomas. Clin Radiol 2005; 60: 1039-1050.

9. Falconi M, Bettini R, Boninsegna L, Crippa S, Butturini G, Pederzoli P. Surgical strategy in the treatment of pancreatic neuroendocrine tumors. JOP. 2006; 7: 150-156
Austin J Clin Case Rep - Volume 5 Issue 1 - 2018

ISSN : 2381-912X | www.austinpublishing group.com

Mansour et al. () All rights are reserved
Citation: Mansour M, Salman R, Ahmad I and Alloush A. Case of Insulinoma Misdiagnosed as a Psychiatric Condition for Five Months in Lattakia, Syria. Austin J Clin Case Rep. 2018; 5(1): 1125. 